\title{
PENGARUH DISIPLIN DAN LINGKUNGAN KERJA TERHADAP KINERJA KARYAWAN (Studi pada PT. Tanjung Selatan Makmur Jaya Kalimantan Selatan)
}

\author{
Herlina Lusiana \\ herlina.uniska@gmail.com
}

Firdaus

ampuh53@gmail.com

Universitas Islam Kalimantan Muhammad Arsyad Al Banjari Banjarmasin

\begin{abstract}
This research aims to: (1) tested the influence of the discipline of work partially on performance of employees; (2) to test the influence of partially working environment on performance of employees; (3) test the influence of the discipline of work and work environment on performance of employees simultaneously.

This research was conducted on the PT Tanjung Selatan Makmur Jaya South Kalimantan. There are 71 respondents that have been selected as the sample slovin formula and using the technique of random sampling. Research method using the methods of survey and the type of quantitative research. While the nature of this research including research eksplanatory. Data retrieval method using questionnaires, while data analysis techniques using multiple linear regression and hypothesis testing using IBM SPSS program Version 24.

The results showed that the discipline of work $\left(\mathrm{X}_{1}\right)$ has a partial influence on performance of employees at PT Tanjung Selatan Makmur Jaya South Kalimantan, the working environment $\left(\mathrm{X}_{2}\right)$ has a partial influence on performance of employees on PT Tanjung Selatan Makmur Jaya South Kalimantan, and discipline work $\left(\mathrm{X}_{1}\right)$ and the work environment $\left(\mathrm{X}_{2}\right)$ features simultaneously influence on performance of employees at PT Tanjung Selatan Makmur Jaya South Kalimantan. From the results of the determination coefficient $\left(\mathrm{R}^{2}\right)$ of $73 \%$ change in the performance of the employees of PT Tanjung Selatan Makmur Jaya South Kalimantan affected by variable discipline of work and work environment. While the rest of IE $27 \%$ affected other factors.
\end{abstract}

Keywords: discipline work, the work environment, performance. 


\section{PENDAHULUAN}

Dalam perkembangan industri sekarang ini, perusahaan harus mencari alternatif untuk meningkatkan produksinya. Kesuksesan dari kinerja perusahaan bisa dilihat dari kinerja yang dicapai oleh karyawannya oleh sebab itu perusahaan menuntut agar para karyawannya mampu menampilkan kinerja yang optimal karena baik buruknya kinerja yang dicapai oleh karyawan akan berpengaruh pada kinerja dan keberhasilan perusahaan secara keseluruhan.

PT. Tanjung Selatan Makmur Jaya Kalimantan Selatan yang beralamat di Desa Beringin, Kecamatan Alalak, Kabupaten Barito Kuala Provinsi Kalimantan Selatan merupakan perusahaan industri olahan kayu lapis seperti plywood, doorskin, blockboard (papan blok), wood working berupa komponen set, dan fancy/parquet flooring (lantai papan untuk dekoratif). Berdiri pada tanggal 15 Juni 1981 di Jakarta dengan notaris Ny. Darwani Sidi Bakaroeddin, S.H. Perusahaan mulai melakukan produksi komersil pada pertengahan tahun 1983. Orientasi produksi perusahaan di ekspor khususnya ke Amerika Serikat, Jepang dan Eropa.

Permasalahan yang terjadi saat ini di PT. Tanjung Selatan Makmur Jaya Kalimantan Selatan terkait kinerja karyawannya. Berikut data yang diperoleh mengenai grafik peningkatan jumlah karyawan yang kehadirannya tidak tepat waktu:

\section{Grafik 1. Data Kehadiran Karyawan Tahun 2017}

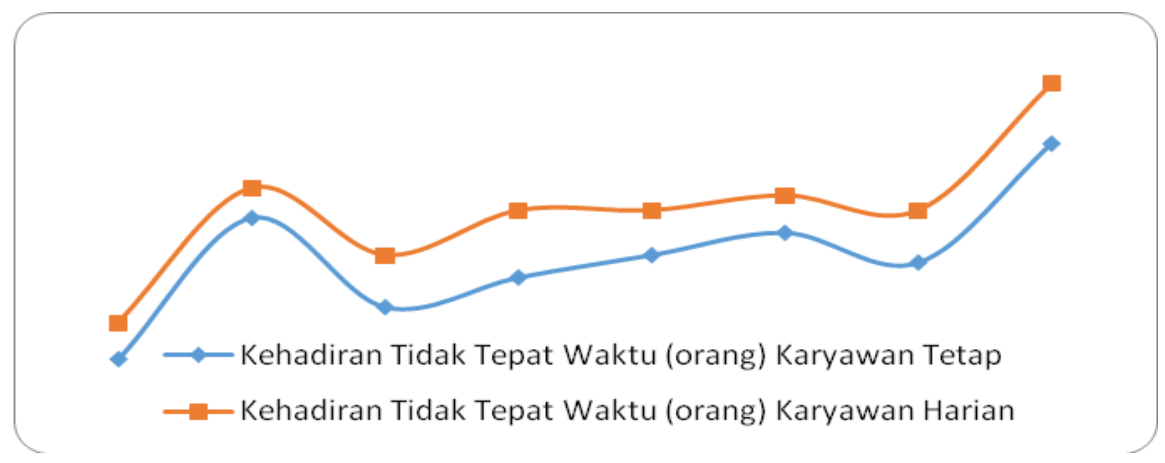

Sumber: HRD PT Tanjung Selatan Makmur Jaya, 2017 
Dari Grafik 1di atas, menunjukan peningkatan jumlah karyawan yang kehadirannya tidak tepat waktu baik karyawan tetap maupun karyawan harian. Hal tersebut indikator awal menurunya kinerja karyawan. Menurut Rivai dan Sagala (2013) kinerja karyawan adalah perilaku nyata yang ditampilkan setiap karyawan sebagai prestasi kerja yang dihasilkan sesuai dengan perannya dalam perusahaan.

\section{Banyak Faktor-faktor yang} mempengaruhi penurunan kinerja karyawan diantaranya disiplin kerja dan lingkungan kerja. Penelitian ini meneliti tentang disiplin kerja dan lingkungan kerja. Mangkunegara (2013) disiplin kerja merupakan pelaksanaan manajemen untuk memperteguh pedoman-pedoman organisasi.

Sedangkan Sri Widodo (2015) lingkungan kerja merupakan lingkungan dimana para karyawan dapat melaksanakan tugasnya sehari-hari dengan keseluruhan sarana dan prasarana kerja yang diperlukan untuk melaksanakan tugas-tugas tersebut.

Untuk memperkuat penelitian ini, terdapat research gap terkait dengan hasil penelitian terdahulu tentang pengaruh disiplin kerja dan lingkungan kerja terhadap kinerja karyawan. Diantaranya hasil penelitian disiplin kerja yang dilakukan Yoga Arsyenda (2013), menyatakan bahwa disiplin kerja berpengaruh positif dan signifikan terhadap kinerja. Sedangkan pada penelitian Galih Rakasiwi (2015), menunjukkan hasil yang berbeda bahwa disiplin kerja berpengaruh negatif signifikan terhadap kinerja pegawai.

Selanjutnya hasil penelitian lingkungan kerja yang dilakukan Artana (2012) dari hasil penelitiannya menyimpulkan bahwa lingkungan kerja berpengaruh positif dan signifikan terhadap kinerja karyawan. Sedangkan hasil penelitian yang dilakukan oleh Arianto (2013) hasil penelitian menyimpulkan lingkungan kerja tidak berpengaruh signifikan terhadap kinerja karyawan.

Adapun penelitian ini bertujuan untuk: (1) menguji pengaruh disiplin kerja secara parsial terhadap kinerja karyawan; (2)menguji pengaruh lingkungan kerja secara parsial terhadap kinerja karyawan; (3) menguji pengaruh disiplin kerja dan lingkungan kerja secara simultan terhadap kinerja karyawan. 


\section{METODE PENELITIAN}

Metode penelitian yang dipakai adalah metode survey. Dengan metode ini data dikumpulkan berdasarkan jawaban responden atas daftar pertanyaan yang peneliti ajukan melalui pengisian daftar pertanyaan (kuesioner) kepada sejumlah responden.Adapun jenis penelitian ini adalah penelitian kuantitatif dan bermaksud untuk menjelaskan pengaruh antar variabel melalui pengujian hipotesis dan sekaligus melakukan eksplanasi terhadap beberapa variabel, maka sifat penelitian ini adalah penelitian eksplanatori, yaitu penelitian yang bertujuan menganalisis hubungan-hubungan antara satu variabel dengan variabel lain atau bagaimana suatu mempengaruhi variabel lain.

Populasi dalam penelitian ini adalah seluruh karyawan PT. Tanjung Selatan Makmur Jaya Kalimantan Selatan yang berjumlah 250 orang. Sampel penelitian berjumlah 71 orang. Penentuan jumlah sampelmenggunakan rumus slovin dengan error estimasi $10 \%$.

Instrumen penelitian digunakan untuk mengukur variabel yang diteliti dengan cara pemberian skor. Pengukuran variabel penelitian ini dilakukan melalui kuesioner yang disebar kepada responden. Dalam pengukuran jawaban responden, pengisian kuesioner variabel disiplin kerja, lingkungan kerja dan kinerja karyawan diukur dengan menggunakan skala Likert dapat diliat pada tabel berikut:

Tabel 1

Skala Likert dan Bobot Nilai Jawaban Responden

\begin{tabular}{|c|c|}
\hline $\begin{array}{c}\text { Alternative } \\
\text { Jawaban }\end{array}$ & $\begin{array}{c}\text { Bobot } \\
\text { Nilai }\end{array}$ \\
\hline Sangat Setuju (SS) & 5 \\
\hline Setuju (S) & 4 \\
\hline Ragu-Ragu (RR) & 3 \\
\hline Tidak Setuju (TS) & 2 \\
\hline $\begin{array}{c}\text { Sangat Tidak } \\
\text { Setuju (STS) }\end{array}$ & 1 \\
\hline
\end{tabular}

Teknik pengumpulan data dilakukan dengan menyebar kuesioner yang merupakan indikator-indikator yang digunakan dalam penelitian ini dan berupa daftar pertanyaan yang telah ditentukan.

Kriteria pengujian validitas kuesionerlayak atau tidaknya suatu item yang digunakan biasanya dilakukan uji signifikansi 0,05 artinya suatu item dianggap valid jika berkorelasi signifikan terhadap skor total.Atau jika melakukan penelitian langsung terhadap koefisien korelasi, dapat digunakan batas nilai minimal korelasi 0,30 .Sugiyono 
(2004). Kriteria pengujian reliabilitas diukur dengan uji statistik cronbach's alpha $(\alpha)$. Suatu variabel dikatakan reliabel jika memberikan nilai cronbach' alpha $>$ 0,60. Ghozali (2007).

Analisis regresi linier berganda digunakan untuk mengetahui pengaruh variabel bebas yaitu disiplin kerja $\left(\mathrm{X}_{1}\right)$ dan lingkungan kerja $\left(\mathrm{X}_{2}\right)$ terhadap variabel terikat, yaitu kinerja karyawan (Y).

\section{HASIL DAN PEMBAHASAN}

Berdasarkan hasil analisis data menggunakan SPSS Versi 24menunjukan hasil analisis regresi linier berganda pada Tabel 2 di bawah ini:

Tabel 2

Hasil Analisis Regresi Linier Berganda

\begin{tabular}{|c|c|c|c|c|c|c|}
\hline \multirow{2}{*}{\multicolumn{2}{|c|}{ Model }} & \multicolumn{2}{|c|}{$\begin{array}{l}\text { Unstandardized } \\
\text { Coefficients }\end{array}$} & \multirow{2}{*}{$\begin{array}{c}\text { Standardized } \\
\text { Coefficients } \\
\text { Beta }\end{array}$} & \multirow[b]{2}{*}{$\mathrm{t}$} & \multirow[b]{2}{*}{ Sig. } \\
\hline & & B & $\begin{array}{l}\text { Std. } \\
\text { Error }\end{array}$ & & & \\
\hline \multirow[t]{3}{*}{1} & (Constant) & 3.827 & 1.501 & & 2.549 & .013 \\
\hline & Disiplin Kerja (X1) & .310 & .046 & .517 & 6.771 & .000 \\
\hline & $\begin{array}{l}\text { Lingkungan Kerja } \\
\text { (X2) }\end{array}$ & .616 & .105 & .449 & 5.884 & .000 \\
\hline
\end{tabular}

Sumber: data primerdiolah, 2017

Berdasarkan hasil analisis regresi linier berganda pada Tabel 2 di atas, maka model persamaan regresi linier berganda adalah:

$$
\begin{aligned}
& \mathrm{Y}=3,827+0,310\left(\mathrm{X}_{1}\right)+0,616\left(\mathrm{X}_{2}\right) \\
& \text { Dari persamaan tersebut dapat }
\end{aligned}
$$
dijelaskan sebagai berikut:

Nilai konstanta adalah 3,827 menyatakan bahwa tanpa adanya variabel bebas yaitu variabel Disiplin
Kerja $\left(\mathrm{X}_{1}\right)$ dan Lingkungan Kerja $\left(\mathrm{X}_{2}\right)$ nilai variabel terikat yaitu kinerja karyawan PT. Tanjung Selatan Makmur Jaya Kalimantan Selatan sebesar 3,827 satuan.

Nilai koefisien regresi dari variabel disiplin kerja $\left(\mathrm{X}_{1}\right)$ adalah 0,310 menyatakan bahwa jika nilai variabel Disiplin Kerja $\left(\mathrm{X}_{1}\right)$ ditingkatkan satu satuan maka akan menyebabkan 
perubahan nilai kinerja karyawan PT. atau nol.Selanjutnya dari hasil Tanjung Selatan Makmur Jaya perhitungan Tabel 2 model persamaan Kalimantan Selatan(Y) sebesar 0,310 regresi linear berganda diatas satuan. Dengan asumsi bahwa nilai dari variabel lain adalah konstan atau nol.

Nilai koefisien regresi dari variabel lingkungan kerja $\left(\mathrm{X}_{2}\right)$ adalah 0,616 menyatakan bahwa jika nilai variabel lingkungan kerja $\left(\mathrm{X}_{2}\right)$ ditingkatkan satu satuan maka akan menyebabkan perubahan nilai kinerja karyawan PT. Tanjung Selatan Makmur Jaya Kalimantan Selatan (Y) sebesar 0,616 satuan. Dengan asumsi bahwa nilai dari variabel lain adalah konstan menunjukkan adanya hubungan antara kinerja (Y) sebagai variabel terikat dan variabel disiplin kerja $\left(\mathrm{X}_{1}\right)$ dan lingkungan kerja $\left(\mathrm{X}_{2}\right)$ sebagai variabel bebas memiliki pengaruh yang positif.

Hasil pengujian hipotesis

Berdasarkan hasil analisis data menggunakan SPSS Versi 24 menunjukan hasil hasil pengujian hipotesis secara parsial (Uji t) pada Tabel 3 di bawah ini:

Tabel 3

\section{Hasil Pengujian Hipotesis Secara Parsial (Uji t)}

\begin{tabular}{|c|c|c|c|c|c|c|c|}
\hline \multirow{2}{*}{\multicolumn{2}{|c|}{ Model }} & \multicolumn{2}{|c|}{$\begin{array}{c}\text { Unstandardized } \\
\text { Coefficients }\end{array}$} & \multirow{2}{*}{$\begin{array}{c}\text { Standardized } \\
\text { Coefficients } \\
\text { Beta }\end{array}$} & \multirow{2}{*}{$\mathrm{t}$ hitung } & \multirow{2}{*}{$\mathrm{t}_{\text {tabel }}$} & \multirow[b]{2}{*}{ Sig. } \\
\hline & & B & Std. Error & & & & \\
\hline \multirow[t]{3}{*}{1} & (Constant) & 3.827 & 1.501 & & 2.549 & & .013 \\
\hline & $\begin{array}{l}\text { Disiplin Kerja } \\
\text { (X1) }\end{array}$ & .310 & .046 & .517 & 6.771 & 0,2335 & .000 \\
\hline & $\begin{array}{l}\text { Lingkungan } \\
\text { Kerja (X2) }\end{array}$ & .616 & .105 & .449 & 5.884 & 0,2335 & .000 \\
\hline
\end{tabular}

Sumber: data primerdiolah, 2017

1. Pengujian Hipotesis Pertama

Dari Tabel 3 di atas, diperoleh variabel disiplin kerja nilai $\mathrm{t}$ hitung sebesar 6,771 > t tabel 0,2335 atau nilai signifikansi $0,000<0,05$ ini menunjukan bahwa variabel disiplin kerja $\left(\mathrm{X}_{1}\right)$ berpengaruh secara parsial terhadap kinerja karyawan PT. Tanjung Selatan 
Makmur Jaya Kalimantan Selatan. Jadi, hipotesis pertama yaitu terdapat pengaruh disiplin kerja secara parsial terhadap kinerja karyawan pada PT. Tanjung Selatan Makmur Jaya Kalimantan Selatan terbukti danditerima.

2. Pengujian Hipotesis Kedua

Dari Tabel 3di atas, diperoleh variabel lingkungan kerja $\left(\mathrm{X}_{2}\right)$ nilai $\mathrm{t}$ hitung sebesar 5,884 > t tabel 0,2335 atau nilai signifikansi $0,000<0,05$ ini menunjukan bahwa variabel lingkungan kerja $\left(\mathrm{X}_{2}\right)$ berpengaruh secara parsial terjadap kinerja karyawan PT. Tanjung
Selatan Makmur Jaya Kalimantan Selatan. Jadi hipotesis kedua yaitu terdapat pengaruh lingkungan kerja secara parsial terhadap kinerja karyawan pada PT. Tanjung Selatan Makmur Jaya Kalimantan Selatan terbukti dan diterima.

\section{Pengujian Hipotesis Ketiga \\ Berdasarkan hasil analisis data menggunakan SPSS Versi 24menunjukan hasil hasil pengujian hipotesis secara simultan (Uji F)pada Tabel 4 di bawah ini:}

Tabel 4

\section{Hasil Pengujian Hipotesis Secara Simultan (Uji F)}

\begin{tabular}{|c|c|c|c|c|c|c|c|}
\hline \multicolumn{2}{|c|}{ Model } & $\begin{array}{l}\text { Sum of } \\
\text { Squares }\end{array}$ & df & Mean Square & $\mathrm{F}_{\text {Hitung }}$ & $\mathrm{F}_{\text {Tabel }}$ & Sig. \\
\hline \multirow[t]{3}{*}{1} & Regression & 1241.538 & 2 & 620.769 & 92.085 & 0,2335 & .000 \\
\hline & Residual & 458.406 & 68 & 6.741 & & & \\
\hline & Total & 1699.944 & 70 & & & & \\
\hline
\end{tabular}

Sumber: data primer diolah, 2017

Dari Tabel 4 di atas, diperoleh Hasil Uji F di atas menunjukkan nilai FHitung sebesar 92,85> $\mathrm{F}_{\text {Tabel }} 0,2335$ atau signifikansi sebesar $0,000<0,05$. Hal ini berarti bahwa hipotesis ketiga yang menyatakan yaitu terdapat pengaruh disiplin kerja kerja dan lingkungan kerja secara simultan terhadap kinerja karyawan pada PT. Tanjung Selatan Makmur Jaya Kalimantan Selatan terbukti dan diterima. 


\section{Koefisien Determinasi $\left(\mathrm{R}^{2}\right)$}

Berdasarkan hasil analisis data menggunakan SPSS Versi 24menunjukan nilai koefisien korelasi pada Tabel 5di bawah ini:

\section{Tabel 5}

\section{Hasil Koefisien Determinasi $\left(\mathbf{R}^{2}\right)$}

\begin{tabular}{|c|c|c|c|c|c|c|c|}
\hline \multirow[b]{2}{*}{ Model } & \multirow[b]{2}{*}{$\mathrm{R}$} & \multirow[b]{2}{*}{$\begin{array}{c}\mathrm{R} \\
\text { Square }\end{array}$} & \multirow[b]{2}{*}{$\begin{array}{l}\text { Adjusted R } \\
\text { Square }\end{array}$} & \multirow[b]{2}{*}{$\begin{array}{l}\text { Std. Error of } \\
\text { the Estimate }\end{array}$} & \multicolumn{3}{|c|}{ Change Statistics } \\
\hline & & & & & $\begin{array}{l}\text { R Square } \\
\text { Change }\end{array}$ & $\begin{array}{c}\text { F } \\
\text { Change }\end{array}$ & df1 \\
\hline 1 & $.855^{\mathrm{a}}$ & .730 & .722 & 2.596 & .730 & 92.085 & 2 \\
\hline
\end{tabular}

Sumber: Data primer diolah (2017)

Berdasarkan output model summary, diketahui nilai koefisien determinasi ( $R$ Square) sebesar 0,730 yang berarti 73\% disiplin kerja dan lingkungan kerja berpengaruh terhadap kinerja. Sedangkan sisanya $27 \%$ dipengaruhi oleh faktor lain di luar model regresi ini.

\section{PEMBAHASAN PENELITIAN}

Berdasarkan hasil penelitian diketahui kemampuan koefisien determinasi $\quad\left(\mathrm{R}^{2}\right) \quad$ sebesar $\quad 0,730$ menunjukkan bahwa $73 \%$ perubahan kinerja pegawai PT. Tanjung Selatan Makmur Jaya Kalimantan Selatan dipengaruhi oleh variabel disiplin kerja dan lingkungan kerja. Sedangkan sisanya yaitu sebesar $27 \%$ perubahan kinerja karyawan PT. Tanjung Selatan Makmur Jaya Kalimantan Selatan dipengaruhi variabel-variabel di luar variabel yang diamati tersebut, misalnya: etos kerja, komunikasi, kepemimpinan dan lain lain.Koefisien korelasi berganda $\left(\mathrm{R}^{2}\right)$ sebesar 0,730 yang menunjukkan adanya pengaruh yang kuat antara variabel disiplin kerja dan lingkungan kerja terhadap kinerja pegawai PT. Tanjung Selatan Makmur Jaya Kalimantan Selatan.

Hasil pengujian hipotesis pertama menunjukkan nilai signifikansi sebesar $0,000<0,05$. Hal ini berarti disiplin kerja berpengaruh secara parsial terhadap kinerja karyawan PT. Tanjung Selatan Makmur Jaya Kalimantan Selatan . Nilai tHitung 6,771 menunjukkan motivasi memiliki pengaruh positif terhadap kinerja karyawan. Semakin tinggi disiplin kerja maka semakin tinggi 
pula kinerja, sementara semakin rendah disiplin kerja maka semakin rendah kinerja karyawan PT. Tanjung Selatan Makmur Jaya Kalimantan Selatan. Hasil penelitian ini mendukung penelitian terdahulu yang dilakukan oleh Yoga Arsyenda (2013), menyatakan bahwa disiplin kerja berpengaruh positif dan signifikan terhadap kinerja.

Hasil pengujian hipotesis kedua menunjukkan nilai signifikansi sebesar $0,000<0,05$. Hal ini berarti lingkungan kerja berpengaruh secara parsial terhadap kinerja karyawan PT. Tanjung Selatan Makmur Jaya Kalimantan Selatan. Nilai thitung 5,884 menunjukkan lingkungan kerja memiliki pengaruh positif terhadap kinerja karyawan. Semakin tinggi lingkungan kerja karyawan maka semakin tinggi pula kinerjanya. Sementara semakin rendah lingkungan kerja maka semakin rendah pula kinerja karyawan PT. Tanjung Selatan Makmur Jaya Kalimantan Selatan. Hasil penelitianini mendukung penelitian terdahulu Artana (2012) dari hasil penelitiannya menyimpulkan bahwa lingkungan kerja berpengaruh positif dan signifikan terhadap kinerja karyawan.

Hasil pengujian hipotesis ketiga menunjukkan nilai signifikansi sebesar
$0,000<0,05$. Hal ini berarti lingkungan kerja berpengaruh secara parsial terhadap kinerja karyawan PT. Tanjung Selatan Makmur Jaya Kalimantan Selatan. Hal ini berarti disiplin kerja dan lingkungan kerja secara simultan memiliki pengaruh besar terhadap kinerja karyawan PT. Tanjung Selatan Makmur Jaya Kalimantan Selatan. Semakin tinggi disiplin kerja dan lingkungan kerja yang mendukung maka semakin setuju pula kinerja karyawan PT. Tanjung Selatan Makmur Jaya Kalimantan Selatan. Semakin kurang disiplin kerja dan lingkungan kerja yang maka semakin kurang pula kinerja karyawan PT. Tanjung Selatan Makmur Jaya Kalimantan Selatan.

\section{KESIMPULAN DAN SARAN}

Berdasarkan pembahasan hasil penelitian, dapat disimpulkan hal-hal penting sebagai berikut:

1. Terdapat pengaruh disiplin kerja secara parsial terhadap kinerja karyawan pada PT. Tanjung Selatan Makmur Jaya Kalimantan Selatan. Dibuktikan dengan nilai $\mathrm{t}$ hitung sebesar $6,771>\mathrm{t}$ tabel 0,2335 atau nilai signifikansi $0,000<0,05$.

2. Terdapat pengaruh lingkungan kerja secara parsial terhadap kinerja karyawan pada PT. Tanjung Selatan 
Makmur Jaya Kalimantan Selatan. Dibuktikan dengan nilai $\mathrm{t}$ hitung sebesar 5,884 > t tabel 0,2335 atau nilai signifikansi $0,000<0,05$.

3. Terdapat pengaruh disiplin kerja dan lingkungan kerja secara simultan terhadap kinerja karyawan pada PT. Tanjung Selatan Makmur Jaya Kalimantan Selatan. Dibuktikan nilai $F_{\text {Hitung }}$ sebesar 92,85> $F_{\text {Tabel }} 0,2335$ atau signifikansi sebesar $0,000<0,05$.

\section{SARAN DAN IMPLIKASI}

Berdasarkan hasil pembahasan dan kesimpulan penelitian, maka dapat diberikan saran sebagai berikut:

1. Untuk memperbaiki kinerja karyawan dapat dilakukan dengan cara meningkatkan disiplin kerja dan lingkungan kerja PT. Tanjung Selatan Makmur Jaya Kalimantan Selatan secara bertahap.

2. Untuk meningkatkan disiplin kerja dilakukan dengan cara memberikan intensif dan bonus yang sesuai dengan prestasi kerja karyawan.

3. Untuk lingkungan kerja dapat diperbaiki dengan meningkatkan kualitas hubungan antara karyawan dan pimpinan perusahaan, maupun dengan sesama karyawan.
4. Penelitian selanjutnya, sebaiknya melakukan penelitian dengan variabel lainnya seperti insentif dan bonus.

\section{DAFTAR PUSTAKA}

Arsyenda, Yoga. 2013. "Pengaruh Motivasi Kerja dan Disiplin Kerja Terhadap Kinerja PNS (Studi Kasus: BAPPEDA Kota Malang)". Jurnal Ilmiah. Malang: Fakultas Ekonomi dan Bisnis, Universitas Brawijaya.

Arianto, Nugroho Agung Dwi. 2013. Pengaruh Kedisiplinan, Lingkungan Kerjadan Budaya Kerja Terhadap Kinerja Tenaga Pengajar. Dalam Jurnal Universitas Islam Nahdlatul Ulama, Hal 198-120 Jepara: Universitas Islam Nahdlatul Ulama.

Artana, I Wayan Arta. 2012. Pengaruh Kepemimpinan, Kompensasi, dan Lingkungan Kerja terhadap Kinerja Karyawan Studi Kasus di Maya Ubud Resto \& SPA. Jurnal Perhotelan dan Pariwisata. Vol. 2. No. 1. Hal. 66 - 80 Denpasar Bali: STIPAR Triatma Jaya).

Galih Rakasiwi. 2015. "Pengaruh Motivasi, Kepuasan Kerja, dan Disiplin Kerja Terhadap Kinerja Pegawai (Studi Empiris pada Satuan Polisi Pamong Praja Kabupaten Karanganyar)". Jurnal Ekonomi dan Bisnis. Surakarta: Universitas Muhammadiyah Surakarta, Vol1, No.2.

Ghozali, Imam. 2009. Ekonometrika Teori, Konsep dan Aplikasi dengan SPSS17.Semarang: 
AL - ULUM ILMU SOSIAL DAN HUMANIORA

ISSN: $2476-9576$

Volume 4 Nomor 1, April 2018

Badan Penerbit Universitas Diponegoro.

Mangkunegara, A. A. Anwar Prabu. 2013. Manajemen Sumber Daya Manusia. Jakarta: Rineka Cipta.

Rivai, Veithzal dan Ella Djauhari Sagala, 2013. Manajemen Sumbert Daya Manusia Untuk Perusahaan. Jakarta: Rajawali Pers.

Sugiyono. 2014. Metode Penilitian Kuantitatif, Kualitatif, dan $R \& D$. Bandung: Alfabeta.

Sri Widodo Soedarso. 2015. Manajemen Sumber Daya Manusia. Bandung: Manggu Media. 